\title{
ALIH KODE DAN CAMPUR KODE GURU-SISWA DALAM PEMBELAJARAN TEMATIK KELAS V SEKOLAH DASAR NEGERI O5 INDRALAYA KABUPATEN OGAN ILIR
}

\author{
OLEH \\ Novita Aryani \\ Magister Pendidikan Bahasa dan Sastra Indonesia Universitas PGRI Palembang \\ Email: novitaaryani75@gmail.com
}

\begin{abstract}
ABSTRAK
Penelitian ini bertujuan untuk mengetahui dan mendeskripsikan alih kode dan campur kode guru-siswa dalam pembelajaran tematik kelas V Sekolah Dasar Negeri 05 Indralaya Kabupaten ogan Ilir yang berlokasi di Desa Indralaya kelurahan Indralaya Mulya. Metode yang digunakan dalam peneltian ini adalah metode deskriptif kualitatif. Teknik pengumpulan data menggunakan teknik rekam, simak, dilanjutkan dengan teknik catat. Hasil penelitian menunjukkan adanya fenomena alih kode dan campur kode, wujud alih kode, dan Campur kode, fungsi alih kode dan campur kode. Faktor-faktor yang melatarbelakangi terjadinya alih kode dan campur kode. Dampak positif alih kode dan campur kode guru-siswa dalam pembelajaran tematik kelas V Sekolah Dasar Negeri 05 Indralaya Kabupaten Ogan Ilir, adalah proses belajar mengajar dapat berjalan dengan lancar, baik bagi guru maupun siswa itu sendiri. Pengaruh negatif penggunaan alih kode dan campur kode yaitu rusaknya tatanan bahasa Indonesia yang diakibatkan terjadinya interferensi dan integrasi, penggunaan bahasa Indonesia tidak dilakukan dengan baik dan benar sehingga dalam pembelajaran situasi menjadi tidak formal.
\end{abstract}

Kata Kunci: alih kode, campur kode, pembelajaran, tematik.

\begin{abstract}
This study aims to determine and describe code switching and student-teacher code mixing in the thematic learning of Class V of 05 State Elementary School, Indralaya, Ogan Ilir Regency, located in Indralaya Village, Indralaya Mulya Village. The method used in this research is descriptive qualitative method. Data collection techniques using the record technique, see, followed by note technique. The results showed a phenomenon of code switching and code mixing, code switching, and code mixing, code switching and code mixing functions. Factors underlying the occurrence of code switching and code mixing. The positive impact of code switching and teacher-student code mixing in Thematic Class V 05 Primary School Indralaya Ogan Ilir District teaching and learning process is that the learning process can run smoothly. The negative influence of the use of code switching and code mixing is the destruction of the Indonesian language due to interference and integration, the use of Indonesian is not done properly and correctly so that in learning the situation becomes informal.
\end{abstract}

Keywords: code switching, code mixing, learning, thematic 


\section{PENDAHULUAN}

Bahasa merupakan hal yang paling hakiki dalam kehidupan manusia karena bahasa merupakan alat komunikasi yang digunakan oleh manusia. Chaer dan Agustina (2010:14) mengatakan bahasa adalah alat untuk berinteraksi atau alat untuk berkomunikasi dalam arti alat untuk menyampaikan pikiran, gagasan, konsep, atau juga perasaan. Selain itu bahasa sebagai alat menyatakan ekspresi diri, mengadakan integrasi, dan mengadakan kontrol sosial (Keraf, 1995:3). Kalau kita melihat seseorang memakai dua bahasa dalam pergaulannya dengan orang lain, dia berdwibahasa dalam arti dia melaksanakan kedwibahasaan yang kita sebut dengan bilingualisme. Kedwibahasaan artinya kemampuan atau kebiasaan yang dimiliki oleh penutur dalam menggunakan bahasa (Aslinda dan Syafyahya, 2007:8). Kemultilingualan bahasa dapat terjadi pada semua lapisan masyarakat, baik itu anak-anak, remaja, dewasa, orang tua. kemultilingualan bahasa juga dapat terjadi diberbagai tempat manapun, misalnya di sawah, kantor, kegiatan jual beli antar pedagang dan penjual, bahkan tidak jarang di sekolah-sekolah pun terjadi kedwibahasaan atau multilingual bahasa. Variasi atau keragaman bahasa yang dimiliki individu tersebut seperti bilingualisme atau multilingualisme. Istilah bilingualisme dalam bahasa Indonesia disebut juga kedwibahasaan, kedwibahasaan inilah yang menyebabkan terjadinya alih kode dan campur kode.

Proses belajar mengajar di SDN 05 Indralaya juga terdapat alih kode dan campur kode. Hal tersebut tidak hanya terjadi pada siswa, tetapi juga dapat terjadi pada guru yang mempunyai latar belakang bahasa (bahasa ibu) yang sama denga siswa, seorang guru menggunakan bahasa daerah atau bahasa ibu agar siswa-siswa yang sedang diajarkannya mengerti dengan pembelajaran yang diajarkan, dalam masyarakat umum, campur kode sering terjadi karena bahasa yang satu dengan bahasa yang yang lain dapat saling melengkapi. Menurut Rahardi (2015:25) kode dapat didefinisikan sebagai suatu sistem tutur yang penerapan unsur bahasanya mempunyai ciri khas sesuai dengan latar belakang. Seorang yang melakukan pembicaraan sebenarnya mengirimkan kode-kode kepada lawan bicaranya. Pengkodean ini melalui suatu proses yang terjadi baik pada pembicara, nampak suara, dan pada lawan bicara.

Istilah alih kode berasal dari bahasa Inggris yaitu alih 'switching' dan kode 'code'. Alih kode terdiri atas dua bagian, yaitu kata alih yang berarti 'pindah', sedangkan kode berarti salah satu variasi di dalam tataran bahasa. Dengan demikian secara etimologi, alih kode dapat diartikan sebagai peralihan atau perpindahan dari suatu variasi bahasa ke bahasa yang lain (Suandi, 2014:13). Pembicaraan mengenai ahli kode biasanya diikuti dengan pembicaraan mengenai campur kode. Menurut Rohkman (2013:38) menyatakan campur kode sebagai pemakaian dua bahasa atau lebih dengan saling memasukkan unsur bahasa yang satu ke unsur bahasa yang lain secara konsisten. Percampuran dua atau lebih bahasa atau ragam bahasa dalam suatu tindakan bahasa tanpa ada sesuatu dalam situasi berbahasa itu yang menuntut percampuran bahasa itu. Berdasarkan pendapat ahli di atas, maka campur kode adalah peristiwa pemakaian dua bahasa atau lebih dengan saling memasukkan unsur 
bahasa lain karena adanya beberapa kata atau istilah yang tidak dapat disampaikan sehingga mengharuskan untuk menggunakan bahasa atau ragam bahasa daerah atau bahasa asing.

Kebiasaan anak SD dalam berkomunikasi sehari-hari baik di rumah, sekolah, dan masyarakat menggunkan bahasa daerah atau bahasa ibu membuat mereka sulit mengerti pelajaran yang disampaikan guru dalam bahasa Indonesia, dari sini kita tahu sejauh mana pengaruh alih kode dan campur kode dalam pembelajaran siswa di SD. Berhubungan dengan variasi bahasa, banyak ditemukan masalah variasi bahasa, bahasa yang disebabkan oleh guru dan siswa dari daerah setempat. Karena variasi bahasa yang digunakan guru dan siswa merupakan salah satu komponen utama dalam proses komunikasi sehari-hari antara guru dan siswa. Hal ini pun memicu guru untuk mellibatkan dirinya dalam beberapa fenomena bahasa dalam kegiatan belajar mengajar. Fenomena bahasa yang dimaksud meliputi alih kode dan campur kode yang terjadi pada komunikasi guru dan siswa dalam kegiatan pembelajaran sehari-hari di kelas.

Salah satu sekolah yang diobservasi adalah SDN 05 Indralaya kabupaten Ogan Ilir, berdasarkan hasil survey yang dilakukan peneliti hampir $80 \%$ guru lebih banyak melakukan alih kode dan campur kode, hal ini dikarekan kurang pahamnya siswa dalam menyerap materi yang disampaikan guru dengan menggunakan bahasa Indonesia, dalam keadaan ini guru ditutunt untuk melakukan alih kode dan campur kode agar siswa lebih mudah menyerap materi yang diberikan. Penelitian sejenis yang dilakukan oleh Sri Lorita pada tahun 2003 yang berjudul Alih kode dan Campur Kode Guru-Siswa dalam Interaksi Kelas di
Sekolah Menegah Umum Negeri 11 Palembang. Hasil penelitiannya adalah terdapat keterkaitan penggunaan alih kode dan campur kode dalam bahasa yang digunakan guru dan siswa. Wujud alih kode berupa kata, frasa, dan kallimat, perulangan kata, idiom, dan klausa yang terletak di dalam kesenyapan dan kesenyapan. Fungsifungsi alih kode dan campur kode dalam interaksi kelas yang diidentifikasi adalah untuk memperjelas, mempertegas, memberi komentar, menyandai simpulan atau peralihan topik, mengutip, mengajukan perintah, mengingatkan, mengakrabkan diri, memberikan contoh, menerjemahkan, dan menyampaikan informasi secara cepat. Campur kode dan alih kode guru dan siswa merujuk pada strategi imitasi yang memperlihatkan bahwa komunikasi berjalan dengan baik apabila tujuan pembelajaran tercapai. Kecenderungan guru-siswa beralih kode sesuai dengan kemampuan, pengetahuan, dan sikap positif berbahasa Indonesia yang tertuang dalam tindakan berbahasa dan pencapaian pembelajaran.

Berdasarkan deskripsi tersebut maka rumusan masalah dalam artikel ini adalah:1) bagaimanakah wujud alih kode dan campur kode yang digunakan guru-siswa dalam pembelajaran tematik kelas V SDN 05 Indralaya?, 2) bagaimanakah fungsi alih kode dan campur kode yang digunakan gurusiswa dalam kegiatan pembelajaran tematik kelas V SDN 05 Indralaya?, 3) apakah faktor-faktor yang melatarbelakangi terjadinya alih kode dan campur kode yang digunakan gurusiswa dalam pembelajaran tematik kelas V SDN 05 Indralaya? 4) apa sajakah pengaruh alih kode dan campur kode yang digunakan guru-siswa dalam pembelajaran tematik kelas V SDN 05 
Indralaya?

Berdasarkan rumusan masalah di atas maka tujuan yang ingin dicapai dalam penelitian ini adalah untuk mendeskripsikan dan menjelaskan 1) wujud alih kode dan campur kode gurusiswa dalam pembelajaran tematik kelas V SDN 05 Indralaya, 2) fungsi alih kode dan campur guru-siswa dalam pembelajaran tematik kelas V SDN 05 Indralaya, 3) faktor-faktor yang melatarbelakangi alih kode dan campur kode, 4) pengaruh alih kode dan campur kode guru-siswa dalam pembelajaran tematik kelas V SDN 05 Indralaya.

\section{METODE}

Menurut Sugiyono (2016:2) metode penelitian pada dasarnya merupakan cara ilmiah untuk mendapatkan data dengan tujuan dan kegunaan tertentu. Metode yang digunakan dalam penelitian ini adalah metode deskriptif kualitatif. Menurut Moleong (2018:6) adalah penelitian yang menghasilakan prosedur analisis yang tidak menggunakan prosedur analisis statistik atau cara kuantifikasi lainnya. Yang dimaksud dengan sumber data dalam penelitian adalah subjek dari mana data dapat diperoleh. Apabila peneliti menggunakan kuisioner atau wawancara dalam pengumpulan datanya maka sumber data disebut responden, yaitu orang yang merespon atau menjawab pertanyaan-pertanyaan peneliti, baik pertanyaan tertulis maupun lisan (Arikunto,2010:172). Data dalam penelitian ini terdiri hasil rekaman terhadap percakapan alih kode dan campur kode dalam pembelajaran tematik kelas V Sekolah Dasar Negeri 05 Indralaya Kabupaten Ogan Ilir. Data yang diperoleh dikumpulkan menggunakan metode observasi dan wawancara .
Teknik pengumpulan data yang digunakan dalam penelian ini adalah teknik observasi, teknik catat, dan teknik rekam. Hadi (dikutip Sugiyono, 2016:145) teknik observasi merupakan suatu proses yang kompleks, suatu proses yang tersusun dari berbagai proses biologis dan psikologis. Teknik Catat merupakan bagian dari metode cakap, teknik catat merupakan kegiatan mencatat apa yang dilhat (Mahsun, 2007:132). Pencatatan dilakukan secara langsung pada saat terjadinya percakapan atau interaksi pada dialog interaktif. Teknik rekam maksudnya apa yang dicatat itu dapat di cek kembali dengan rekaman yang dihasilkan (Mahsun, 2007:132). Selain mengamati dan mencatat, ujaran-ujaran yang dijadikan data direkam dengan menggunakan Handphone. Perekaman dilaksanakan secara langsung pada saat terjadinya percakapan pelaksanaannya bersama dengan pngamatan dan pencatatan.

\section{HASIL DAN PEMBAHASAN}

Terdapat empat hasil penelitian yaitu (1) Wujud alih kode dan campur kode yang digunakan guru-siswa dalam pembelajaran tematik kelas V SDN 05 Indralaya, (2) fungsi alih kode dan campur kode yang digunakan gurusiswa dalam pembelajaran tematik kelas V SDN 05 Indralaya, (3) faktor-faktor yang melatarbelakangi terjadinya peristiwa alih kode dan campur kode yang digunakan guru-siswa dalam pembelajaran tematik kelas V SDN 05 Indralaya, (4) Pengaruh atau dampak penggunaan alih kode dan campur kode guru-siswa dalam pembelajaran tematik kelas V SDN 05 Indralaya.

Wujud Alih Kode dan Campur Kode yang Digunakan Guru-Siswa dalam Pembelajaran Tematik Kelas V SDN 05 Indralaya. 
Wujud Alih Kode yang Digunakan Guru-Siswa dalam Pembelajaran Tematik Kelas V SDN 05 Indralaya.

Kholik dkk, 2016:155) sebagai "gejala peralihan pemakaian bahasa karena berubahnya situasi". Berdasarkan hasil dari analisis data wujud alih kode yang digunakan guru-siswa dalam pembelajaran tematik kelas V SDN 05 Indralaya yaitu berupa bahasa formal dan bahasa informal. Dalam percakapan guru dan siswa ditemukan 70 tuturan alih kode berupa bahasa formal dan bahasa informal. Berikut merupakan salah satu contoh alih kode berupa bahasa formal dan bahasa informal.

(1) Guru : Edar, la berapo arai dak masok? (Edar, sudah berapa hari tidak masuk?)

(2) Guru : Coba, ada yang belum hafal Pancasila?

Dari tindak komunikasi di atas guru bertanya kepada siswa dengan memakai bahasa daerah Palembang yaitu menanyakan siswa yang bernama Edar sudah berapa hari tidak masuk, kemudian guru bertanya lagi kepada siswa dengan menggunakan bahasa Indonesia apakah ada siswa yang hafal Pancasila?. Tidak tutur di atas termasuk alih kode berupa bahasa formal dan bahasa Informal.

Wujud Campur yang Digunakan Guru-Siswa dalam Pembelajaran Tematik Kelas V SDN 05 Indralaya.

Menurut Suandi (2014:141) campur kode juga bisa diklasifikasikan berdasarkan tingkat perangkat kebahasaan yaitu campur kode pembentuk kalimat, dan campur kode kategori kata atau bentuk leksikal. Dari hasil rekaman tindak komunikasi gurusiswa dalam pembelajaran tematik kelas V SDN 05 Indralaya selama tiga hari dengan masing-masing dua kali pertemuan, maka didapatlah bentuk campur kode, peneliti tampilkan dalam bentuk tabel sebagai berikut.

Data Campur Kode

\begin{tabular}{|c|l|c|c|l|c|}
\hline $\begin{array}{c}\text { N } \\
\mathbf{0}\end{array}$ & \multicolumn{2}{|c|}{$\begin{array}{c}\text { Campur } \\
\text { Kode } \\
\text { Pembentuk } \\
\text { Kalimat }\end{array}$} & $\begin{array}{c}\text { N } \\
\text { o }\end{array}$ & \multicolumn{2}{c|}{$\begin{array}{c}\text { Campur Kode } \\
\text { Kategori Kata } \\
\text { atau Bentuk } \\
\text { Leksikal }\end{array}$} \\
\hline 1 & Kata & 116 & 1 & Nomina & 21 \\
\hline 2 & Frasa & 44 & 2 & Verba & 72 \\
\hline 3 & Klausa & 20 & 3 & $\begin{array}{l}\text { Adjekti } \\
\text { va }\end{array}$ & 31 \\
\hline 4 & $\begin{array}{l}\text { Campu } \\
\text { Ran }\end{array}$ & 1 & 4 & $\begin{array}{l}\text { Adver } \\
\text { bia }\end{array}$ & 8 \\
\hline & & & 5 & $\begin{array}{l}\text { Numera } \\
\text { lia }\end{array}$ & 20 \\
\hline & & & 6 & Pronomina & 3 \\
\hline
\end{tabular}

Fungsi Alih Kode dan Campur Kode yang Digunakan Guru-Siswa dalam Pembelajaran Tematik Kelas V SDN 05 Indralaya.

Berdasarkan Hasil penelitian yang dilakukam peneliti selama tiga hari di SDN 05 Indralaya ada lima macam fungsi alih kode yaitu, (1) untuk menjelaskan, (2) untuk menanyakan, (3) Untuk menegur, (4) untuk menegaskan, (5) untuk mengingatkan.

Salah satu contoh fungsi alih kode untuk mengingatkan.

Guru : Ingatkan itu..! la dijelaskan kemaren, tempo hari waktu KPK ( Ingatkan itu! Sudah dijelaskan kemarin saat materi KPK.)

Guru : Jadi belajar ini tidak lepas dari perkalian, penjumlahan, pembagian, dasarnya itu perkalian dulu, ontok mencari hasil bage kembali ke kalian juga.

Dari tindak komunikasi di atas guru mengingatkan kepada siswa tentang apa yang dijelaskannya waktu dulu mengenai materi KPK, dan juga 
guru tersebut mengingatkan kalau pembelajaran KPK itu tidak terlepas dari yang namanya perkalian, penjumlahan, pembagian untuk mencari hasil bagi. Sedangkan fungsi campur kode yang ditemukan oleh peneliti yaitu sebagai penyisip kalimat.

Contoh:

Guru : Sekarang dengeri, pelajaran kita yaitu IPA, kagek PKN bergabung ya, dengar! (Sekarang dengarkan, pelajaran kita yaitu IPA, nanti PKN bergabung ya, dengar!).

Pada tindak tutur di atas terdapat penyisipan kata kagek (sebentar), kata kagek merupakan bahasa daerah Palembang yang dicampur dengan bahasa Indonesia pada saat guru berkomunikasi dengan siswa. Fungsi penyisip kata kagek yaitu sebagai penekanan terhadap penyampaian materi yang saling menghubungkan nantinya.

Faktor-Faktor

yang

Melatarbelakangi Terjadinya Alih Kode dan Campur Kode Guru-Siswa dalam Pembelajaran Tematik Kelas V SDN 05 Indralaya.

Dalam penelitian ini peneliti menemukan keempat latar belakang terjadinya alih kode dalam pembelajaran tematik yang dilakukan guru dan siswa kelas V Sekolah Dasar Negeri 05 Indralaya sebagai berikut.

1) Penutur dan Pribadi Penutur

Seorang penutur kadang dengan sengaja beralih kode terhadap mitra tutur karena suatu tujuan. Misalnya mengubah situasi dari resmi menjadi tidak resmi. Tindak komunikasi terlihat ketika kegiatan terjadi kegiatan guru melakukan kegiatan pembelajaran di kelas $\mathrm{V}$ Sekolah Dasar Negeri 05 menggunakan bahasa Palembang dengan tujuan agar siswa lebih mudah memahami materi yang ia sampaikan.

\section{2) Perubahan Situasi Tutur}

Alih kode terjadi karena perubahan situasi dari situasi formal ke informal. Perubahan situasi dalam kegiatan pembelajaran guru-siswa dalam pembelajaran tematik kelas $\mathrm{V}$ SDN 05 Indralaya karena adanya faktor situasi formal menjadi situasi informal, hal demikian terjadi karena adanya seorang siswa yang tidak memakai ikat pinggang dan guru tersebut berpindah tempat dari belakang ke depan lemari buku. Namun hal tersebut berlangsung lama, guru segera mengembalikan ketenangan agar proses pembelajaran tetap berjalan dengan tertib.

\section{3) Perubahan Pokok Pembicaraan}

Pook pembicaraan merupakan salah satu faktor pada seseorang penutur dalam menentukan kode bahasa yang dipilih. Di ruang kelas V SDN 05 Indralaya terlihat kegiatan belajar mengajar yang melibatkan guru dan siswa terlihat pada saat guru sedang menjelaskan materi, lalu guru tersebut menuju lemari untuk mengambil sesuatu, guru tersebut mengira pintu pintu lemati terkunci namun terbuka, dan guru tersebut langsungbertanya kenapa pintu lemari terbuka, situasi tersebut berubah dari guru menjelaskan materi ke pertanyaan mengenai pintu lemari yang terbuka.

\section{4) Kehadiran Orang Ketiga}

Dalam sehingga tindak komunikasi yang terjadi pada kegiatan pembelajaran tematik kelas V SDN 05 Indralaya di mana awalnya guru menyuruh siswa membuka buku halaman 183, lalu tiba-tiba ada 
siswa dari kelas lain ingin meminjam sapu di kelas tersebut sehingga pembicaraan pun beralih dari bahasa Indonesia ke bahasa daerah Palembang.

Berdasarkan hasil penelitian terdapat sembilan faktor-faktor yang melatarbelakangi terjadinya campur kode dalam pembelajaran tematik yaitu:

1) Keterbatasan penggunaan kode

2) Pembicara dan pribadi pembicara

3) Mitra Bicara

4) Tempat tinggal dan waktu pembicaraan

5) Modus pembicaraan

6) Topik

7) Fungsi dan tujuan

8) Ragam dan tingkat tutur bahasa

9) Pokok pembicaraan

\section{Pengaruh Alih Kode dan Campur Kode yang Digunakan Guru-Siwa dalam Pembelajaran Tematik Kelas V SDN 05 Indralaya}

Terdapat dua pengaruh atau dampak dalam penggunaan alih kode dan campur kode yang digunakan gurusiswa dalam pembelajaran tematik kelas V SDN 05 Indralaya yaitu pengaruh negatif dan pengaruh positif. Pengaruh positifnya adalah proses belajar mengajar berjalan lancar, proses pembelajaran akan berlangsug dengan baik karena guru mampu mengimbangi antara kemampuan berbahasa siswa, sehingga materi diterima dengan baik.

Pengaruh negatif dalam penggunaan alih kode dan campur kode adalah rusaknya tatanan bahasa Indonesia yang diakibatkan dari terjadinya interferensi bahasa, dan integrasi, serta adanaya alih kode dan campur kode, penggunaan bahasa Indonesia tidak dilakukan secara baik dan benar sehingga situasi pembelajaran menjadi tidak formal.

\section{SIMPULAN DAN SARAN}

Berdasarkan deskripsi hasil penelitian dan pembahasan, dapat disimpulkan sebagai berikut. 1) wujud alih kode yang digunakan guru-siswa dalam pembelajaran tematik kelas $\mathrm{V}$ SDN 05 Indralaya adalah bahasa formal dan bahasa informal, wujud campur kode terdiri dari campur kode pembentuk kalimat yaitu kata 116 , frasa 44, klausa 20, campuran 1, campur kode kategori kata atau bentuk leksikal nomina 28 , verba 72 , adjektiva 31 , adverbia 8 , numeralia 20 , pronomina 3 . 2) adanya fungsi alih kode dan campur kode yang digunakan guru-siswa dalam pembelajaran tematik kelas V SDN 05 Indralaya yaitu untuk menegaskan, menjelaskan, menanyakan, menegur, mengingatkan, sedangkan fungsi campur kode sebagai penyisip kalimat. 3) faktor-faktor yang mempengaruhi terjadinya alih kode dan campur kode yang digunakan guru-siswa dalam pembelajran tematik kelas V SDN 05 Indralaya yaitu (1) penutur dan pribadi penutur, (2) perubahan situasi tutur, (3) perubahan pokok pembicaraan, (4) kehadiran orang ketiga, (4) keterbatasan penggunaan kode, (5) mitra bicara, (6) tempat tinggal dan waktu pembicaraan. (7) modus pembicaraan, (8) topik, (9) fungsi dan tujuan, (10) ragam dan tingkat tutur bahasa, (11) pokok pembicaraan. 4) terdapat dua dampak positif dan negarif penggunaan alih kode dan campur kode dalam pembelajaran tematik kelas V SDN 05 Indralaya yaitu dampat positif guru dengan mudah dapat menyampaikan materi pembelajaran kepada siswa dan proses belajar mengajar berjalan dengan lancar. Dampak negatifnya yaitu rusaknya tatanan bahasa Indonesia yang diakibatkan dari terjadinya interferensi 
bahasa, integrasi, serta situasi pembelajaran menjadi tidak formal.

Berdasarkan simpulan di atas, dapat dikemukakan saran sebagai berikut. 1) kepada guru diharapkan dapat menggunakan alih kode dan campur kode sesuai situasi dan kondisi sebagai upaya dalam mengatasi kesulitan belajar, 2) penelitian ini dapat dikembangkan lagi dengan melakukan penelitian yang sejenis berhubungan dengan penggunaan alih kode dan campur kode.

\section{DAFTAR PUSTAKA}

Arikunto, Suharsimi. 2010. Prosedur penelitian. Jakara: Rineka Cipta.

Aslinda dan Leni Syafyahya. 2007. Pengantar Sosiolinguistik. Bandung: PT Reflika Aditama

Chaer, Abdul dan Leoni Agustina. 2010. Sosiolinguistik Perkenalan Awal. Jakarta: Rineka Cipta.

Keraf, Gorys. 1994. Komposisi. Jakarta: Nusa Indah.

Mahsun. 2007. Metode Penelitian Bahasa. Jakarta: Rajawali Press.

Moleong, Lexy J. 2018. Metodologi Penelitian Kualitatif. Bandung: PT. Remaja Rosdakarya.

Rahardi, Kuncana. 2010. Kajian Sosiolinguistik. Yogyakarta: Ghalia Indonesia.

Rokhman, Fatur. 2013. Sosiolinguistik Suatu Pendekatan Pembelajaran Bahasa dalam Masyarakat Multikulturan. Semarang: Graha Ilmu.

Suandi, I Nengah. 2014. Sosiolinguistik. Singaraja: Graha Ilmu.

Sugiyono. 2016. Metode Penelitian Kuantitatif, Kualitatif, dan $R \& D$. Bandung: Alfabeta. 
